\title{
Preparation of a Cu-MOF as an Electrode Modifier for the Determination of Carbendazim in Water
}

\author{
Ya-wei Hu ${ }^{1,2, *}$, Wei Wang ${ }^{1,3}$, Huai-en $\mathrm{Li}^{1}$, Qiang-kun $\mathrm{Li}^{2}$ and Ke-ke Niu ${ }^{4}$ \\ ${ }^{1}$ Xi'an University of Technology, Xi'an, Shaanxi, 710048, P.R. China \\ ${ }^{2}$ Yellow River Institute of Hydraulic Research, YRCC, Zhengzhou, Henan, 450003, P.R. China \\ ${ }^{3}$ Xiaolangdi Project Construction \& Management Center, Ministry of Water Resources, Zhengzhou, \\ Henan, 450004, P. R. China \\ ${ }^{4}$ Xinxiang Country Agricultural and Pastoral Bureau, Xinxiang, Henan, 453000, P.R. China \\ *E-mail: huyawei_yrcc@sina.com
}

doi: $10.20964 / 2018.05 .70$

Received: 1 February 2018 / Accepted: 10 March 2018 / Published: 10 April 2018

\begin{abstract}
Using a hydrothermal technique, the present study demonstrated the synthesis of a $\mathrm{Cu}$ metal-organic framework $(\mathrm{Cu}-\mathrm{MOF}),\left[\mathrm{Cu}(\mathrm{adp})(\mathrm{BIB})\left(\mathrm{H}_{2} \mathrm{O}\right)\right]_{n}\left(\mathrm{BIB}=1\right.$,4-bisimidazolebenzene; $\mathrm{H}_{2}$ adp = adipic acid). Carbendazim was successfully detected by an ultra-sensitive and facile electrochemical sensor fabricated based on the $\left[\mathrm{Cu}(\mathrm{adp})(\mathrm{BIB})\left(\mathrm{H}_{2} \mathrm{O}\right)\right]_{n}$-coated $\mathrm{GCE}$ via differential pulse voltammetry. The present study employed $\left[\mathrm{Fe}(\mathrm{CN})_{6}\right]^{3-/ 4-}$ as an electrochemical probe to investigate the electrochemical properties of our developed sensor. The charge transfer rate and electrode surface of the $\left[\mathrm{Cu}(\operatorname{adp})(\mathrm{BIB})\left(\mathrm{H}_{2} \mathrm{O}\right)\right]_{n} / \mathrm{GCE}$ were both more favourable compared to those of the bare GCE. Cyclic voltammetry results suggested a desirable electrochemical performance of our developed sensor towards the detection of carbendazim. Our developed sensor was excellent towards the electrochemical oxidation of the analyte. In addition, the as-prepared electrochemical sensor showed great potential for the detection of carbendazim in water samples.
\end{abstract}

Keywords: $\mathrm{Cu}-\mathrm{MOF}$; Carbendazim; Water sample; Electrochemical determination; $\left[\mathrm{Cu}(\mathrm{adp})(\mathrm{BIB})\left(\mathrm{H}_{2} \mathrm{O}\right)\right]_{n} / \mathrm{GCE}$

\section{$\underline{\text { FULL TEXT }}$}

(C) 2018 The Authors. Published by ESG (www.electrochemsci.org). This article is an open access article distributed under the terms and conditions of the Creative Commons Attribution license (http://creativecommons.org/licenses/by/4.0/). 